\title{
A systematic review and meta-analysis of endoscopic versus open treatment of craniosynostosis. Part 1: the sagittal suture
}

\author{
Han Yan, MD, ${ }^{1}$ Taylor J. Abel, MD, ${ }^{2}$ Naif M. Alotaibi, MD, MSc, ${ }^{1}$ Melanie Anderson, MLIS, ${ }^{3}$ \\ Toba N. Niazi, MD, ${ }^{4}$ Alexander G. Weil, MD, ${ }^{5}$ Aria Fallah, MD, MSc, ${ }^{6}$ John H. Phillips, MD, MA, ${ }^{7}$ \\ Christopher R. Forrest, MD, MSc, ${ }^{7}$ Abhaya V. Kulkarni, MD, PhD, ${ }^{1,2}$ \\ James M. Drake, MBBCh, MSc, ${ }^{1,2}$ and George M. Ibrahim, MD, PhD ${ }^{1,2}$ \\ 1Division of Neurosurgery, Department of Surgery, University of Toronto; ${ }^{2}$ Division of Neurosurgery, The Hospital for Sick \\ Children, Toronto; ${ }^{3}$ Library and Information Services, University Health Network, University of Toronto, Ontario, Canada; \\ ${ }^{4}$ Division of Neurosurgery, Nicklaus Children's Hospital, University of Miami Miller School of Medicine, Miami, Florida; ${ }^{5}$ Division \\ of Neurosurgery, CCHU-Ste-Justine Children's, Montreal, Quebec, Canada; ${ }^{6}$ Department of Neurosurgery, Mattel Children's \\ Hospital, David Geffen School of Medicine at University of California Los Angeles, California; and 'Division of Plastic and \\ Reconstructive Surgery, Department of Surgery, University of Toronto, Ontario, Canada
}

\begin{abstract}
OBJECTIVE In this systematic review and meta-analysis the authors aimed to directly compare open surgical and endoscope-assisted techniques for the treatment of sagittal craniosynostosis, focusing on the outcomes of blood loss, transfusion rate, length of stay, operating time, complication rate, cost, and cosmetic outcome.
\end{abstract}

METHODS A literature search was performed in compliance with the Preferred Reporting Items for Systematic Reviews and Meta-Analyses (PRISMA) guidelines. Relevant articles were identified from 3 electronic databases (MEDLINE, EMBASE, and CENTRAL [Cochrane Central Register of Controlled Trials]) from their inception to August 2017. The quality of methodology and bias risk were assessed using the Effective Public Health Practice Project Quality Assessment Tool for Quantitative Studies. Effect estimates between groups were calculated as standardized mean differences with $95 \%$ Cls. Random and fixed effects models were used to estimate the overall effect.

RESULTS Of 316 screened records, 10 met the inclusion criteria, of which 3 were included in the meta-analysis. These studies reported on 303 patients treated endoscopically and 385 patients treated with open surgery. Endoscopic surgery was associated with lower estimated blood loss $(p<0.001)$, shorter length of stay $(p<0.001)$, and shorter operating time $(p<0.001)$. From the literature review of the 10 studies, transfusion rates for endoscopic procedures were consistently lower, with significant differences in 4 of 6 studies; the cost was lower, with differences ranging from $\$ 11,603$ to $\$ 31,744$ in 3 of 3 studies; and the cosmetic outcomes were equivocal $(p>0.05)$ in 3 of 3 studies. Finally, endoscopic techniques demonstrated complication rates similar to or lower than those of open surgery in 8 of 8 studies.

CONCLUSIONS Endoscopic procedures are associated with lower estimated blood loss, operating time, and days in hospital. Future long-term prospective registries may establish advantages with respect to complications and cost, with equivalent cosmetic outcomes. Larger studies evaluating patient- or parent-reported satisfaction and optimal timing of intervention as well as heterogeneity in outcomes are indicated.

https://thejns.org/doi/abs/10.3171/2018.4.PEDS17729

KEYWORDS craniosynostosis; scaphocephaly; endoscopic; sagittal suture; craniofacial

$\mathrm{T}$ THE incidence of craniosynostosis is estimated to be 3.0-6.4 per 10,000 live births; the majority of the cases are sporadic and a minority occur as part of a syndrome. ${ }^{6,24,29}$ There is a predominance of isolated sagittal synostosis or scaphocephaly, which accounts for more than half of all reported craniosynostosis cases and is estimated to occur at a rate of $1.0-2.5$ in 5000 live births..$^{10,24}$ Indications for surgical management of sagittal synostosis focus heavily on correcting dysmorphism (scaphocephaly) and the remote possibility of resolving elevated intracra-

ABBREVIATIONS EPHPP = Effective Public Health Practice Project; LOS = length of hospital stay; PRISMA = Preferred Reporting Items for Systematic Reviews and Meta-Analyses; SMD = standardized mean difference.

SUBMITTED January 29, 2018. ACCEPTED April 3, 2018.

INCLUDE WHEN CITING Published online July 6, 2018; DOI: 10.3171/2018.4.PEDS17729. 


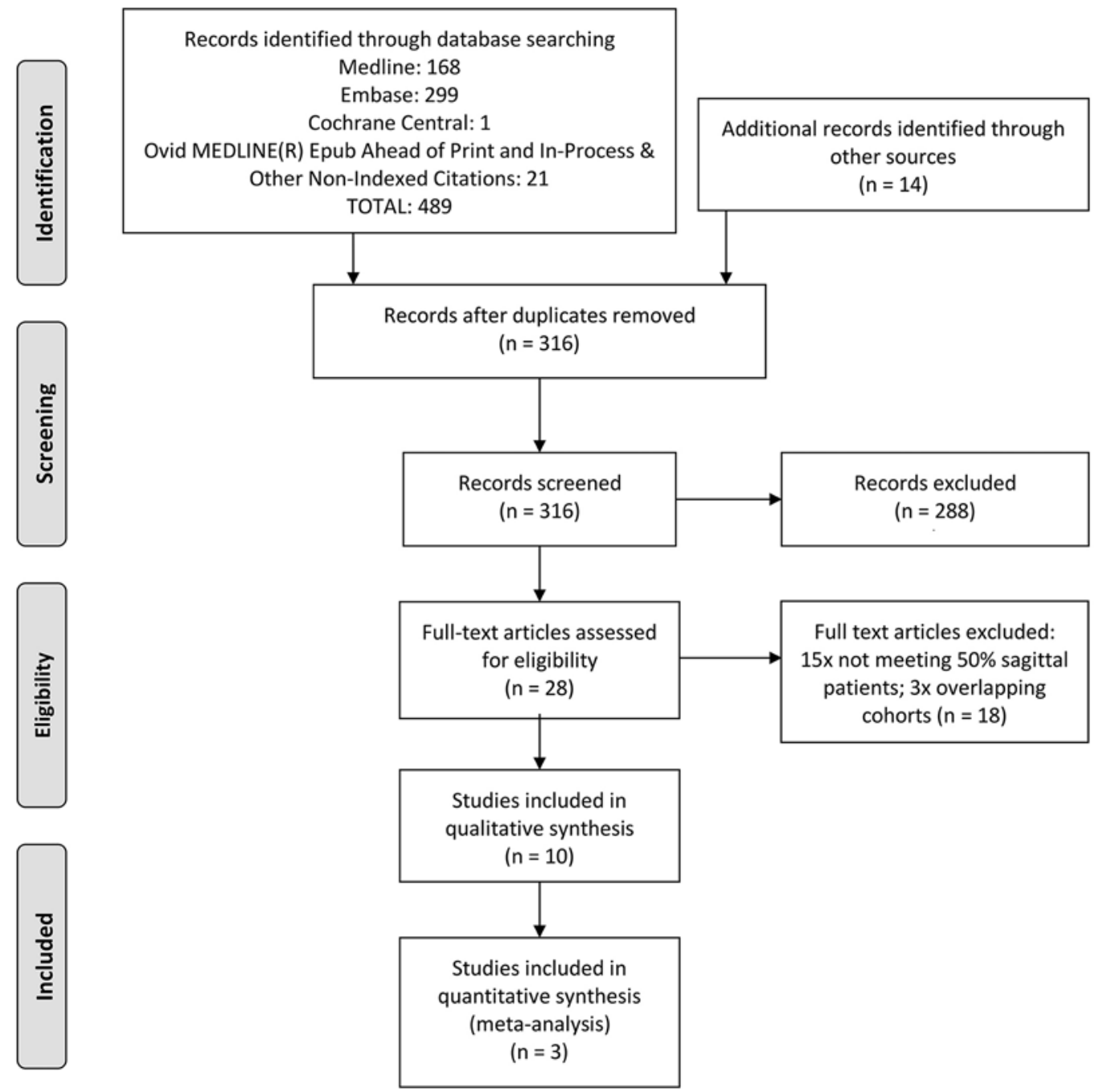

FIG. 1. PRISMA flowchart for systematic review.

nial pressure. It has been hypothesized that untreated sagittal craniosynostosis may lead to early speech and language problems and subsequent literacy issues, and to problems in related functions such as working memory, attention, and planning. ${ }^{20}$ Such adverse outcomes are the result of the elongation of the skull affecting the dorsolateral prefrontal cortex.

Infants with sagittal synostosis can be managed surgically with either traditional open surgery or the more contemporary technique of minimally invasive endoscopeassisted craniectomy followed by helmet therapy. As detailed in Bir et al., ${ }^{3}$ Lannelongue ${ }^{26}$ and Lane ${ }^{25}$ described the earliest treatment of sagittal craniosynostosis relying on suturectomies, and since then the treatment options for sagittal craniosynostosis greatly overshadow those for any other type of craniosynostosis. ${ }^{10}$ Open surgery historically includes a large range of techniques-from strip craniectomy, to the pi procedure, to occipital reductionbiparietal widening, which are each associated with longer operating time, longer hospital stay, and greater blood loss. ${ }^{34}$ Recognizing these suboptimal outcomes, Jimenez and colleagues ${ }^{18,19}$ proposed the novel technique of using endoscopy to perform sagittal suturectomy, followed by 4-6 months of helmet therapy to prevent anteroposterior growth. This technique is offered during the first 6 months of life, optimizing cosmetic and functional results.

Despite numerous adopters of the endoscopic technique, the clinical efficacy of the endoscopic method as it compares to traditional open techniques remains debated. Thus, in this systematic meta-analysis we aimed to directly compare open surgical and endoscope-assisted techniques for the treatment of sagittal craniosynostosis, focusing on the outcomes of blood loss, transfusion rate, length of hospital stay (LOS), operating time, complications, cost, and cosmetic outcome.

\section{Methods}

\section{Search Strategy}

This systematic review and meta-analysis was conducted according to the Preferred Reporting Items for Systematic Reviews and Meta-Analyses (PRISMA) guidelines 
and recommendations. ${ }^{30,40}$ A literature search was performed on MEDLINE, EMBASE, and CENTRAL (Cochrane Central Register of Controlled Trials) on August 17, 2017, by a librarian (M.A.). The database searches used keywords (individually and/or in combination) such as "craniosynostosis," "endoscopic," and "neuroendoscope" with the appropriate subject headings. The reference lists of retrieved articles were reviewed to identify additional relevant articles. An additional search was conducted prior to publication for inclusion of newly published studies.

\section{Study Selection}

Retrieved studies were systematically assessed using inclusion and exclusion criteria by 2 reviewers (H.Y. and T.J.A.). Inclusion criteria were 1) diagnosis of sagittal craniosynostosis by a plastic surgeon or neurosurgeon; 2) at least $50 \%$ of the patient population had isolated sagittal craniosynostosis; 3 ) cohorts were divided into open surgery and endoscopically assisted surgery; and 4) follow-up outcomes were measured at 12 months or more. Exclusion criteria for the meta-analysis included 1) lack of quantitative comparison between open surgery and endoscopically assisted surgery; 2) nonhuman subjects; 3 ) inclusion of patients with syndromic craniosynostosis; and 4) editorials, abstracts, review articles, case reports, and dissertations. When duplicate studies were found, only the most complete reports were included for quantitative assessment. Studies from the same institution and possibly the same cohort of patients were only included if different outcome variables were reported.

\section{Data Extraction and Critical Appraisal}

All data were extracted from article texts, tables, and figures. Each retrieved article was reviewed by 2 investigators independently (H.Y. and T.J.A.). Authors were contacted when there were missing or incomplete data. The quality of the methodology and the risk of bias across studies were assessed by 1 reviewer (H.Y.) using the Effective Public Health Practice Project (EPHPP) Quality Assessment Tool for Quantitative Studies. ${ }^{43}$ Measured variables included selection bias, study design, confounders, blinding, data collection methods, and withdrawals and dropouts, as well as a global rating, and the tool rates each as "strong," "moderate," or "weak."

\section{Statistical Analysis}

Pooled effects between groups were calculated as standardized mean difference (SMD) with 95\% CIs. Interstudy heterogeneity was not applicable because there were only 2 studies for each outcome. We used both random and fixed effects models to estimate the overall effect. A $\mathrm{p}$ value $<0.05$ was set for statistical significance. Analysis was performed on "Comprehensive Meta-analysis" software (version 3.3, BIOSTAT).

\section{Results}

\section{Literature Search}

The search strategy identified a total of 503 studies (Fig. 1). After removal of 187 duplicate studies, inclusion and exclusion criteria were applied to the titles of the remain-
TABLE 1. Exclusion of eligible studies

\begin{tabular}{|c|c|c|}
\hline Authors \& Year & Excluded & Explanations \& Comments \\
\hline Abbott et al., 2012 & No & NA \\
\hline Arts et al., 2018 & No & NA \\
\hline $\begin{array}{l}\text { Bonfield et al., } \\
\quad 2016\end{array}$ & No & NA \\
\hline Chan et al., 2013 & Yes & $\begin{array}{l}\text { Includes pts w/ syndromic craniosyn- } \\
\text { ostosis; pts w/ sagittal craniosyn- } \\
\text { ostosis represent } 33 \% \text { of cohort }\end{array}$ \\
\hline $\begin{array}{l}\text { Dvoracek et al., } \\
2015\end{array}$ & Yes & Overlapping pt population suspected \\
\hline $\begin{array}{l}\text { Esparza \& Hino- } \\
\text { josa, } 2008\end{array}$ & No & NA \\
\hline Farber et al., 2017 & Yes & Pts w/ metopic craniosynostosis only \\
\hline Garber et al., 2017 & No & NA \\
\hline $\begin{array}{l}\text { Ghenbot et al., } \\
2015\end{array}$ & No & NA \\
\hline Ghosh et al., 2014 & Yes & Overlapping pt population suspected \\
\hline Han et al., 2016 & No & $\begin{array}{l}\text { Overlapping pt population confirmed; } \\
\text { included for largest cohort size }\end{array}$ \\
\hline Hashim et al., 2014 & Yes & $\begin{array}{l}\text { Analysis of neuropsychological } \\
\text { outcomes only }\end{array}$ \\
\hline $\begin{array}{l}\text { Keshavarzi et al., } \\
2009\end{array}$ & Yes & Pts w/ metopic craniosynostosis only \\
\hline $\begin{array}{l}\text { Keshavarzi et al., } \\
2010\end{array}$ & Yes & $\begin{array}{l}\text { Pts w/ sagittal craniosynostosis } \\
\text { represent } 45 \% \text { of cohort }\end{array}$ \\
\hline Kohan et al., 2008 & Yes & Case studies of twin pts \\
\hline Le et al., 2014 & Yes & Overlapping pt population suspected \\
\hline $\begin{array}{l}\text { MacKinnon et al., } \\
2009\end{array}$ & Yes & $\begin{array}{l}\text { Pts w/ unilat coronal craniosynosto- } \\
\text { sis only; overlapping pt population } \\
\text { \& data suspected }\end{array}$ \\
\hline $\begin{array}{l}\text { MacKinnon et al., } \\
2013\end{array}$ & Yes & $\begin{array}{l}\text { Pts w/ unilat coronal craniosynosto- } \\
\text { sis only; overlapping pt population } \\
\text { \& data suspected }\end{array}$ \\
\hline Nguyen et al., 2015 & Yes & Pts w/ metopic craniosynostosis only \\
\hline $\begin{array}{l}\text { Nowaková et al., } \\
2015\end{array}$ & Yes & $\begin{array}{l}\text { Translated from Czech; nonquantita- } \\
\text { tive data }\end{array}$ \\
\hline Rogers et al., 2015 & Yes & $\begin{array}{l}\text { Measured outcome is hand prefer- } \\
\text { ence }\end{array}$ \\
\hline Shah et al., 2011 & No & NA \\
\hline Siu et al., 2014 & Yes & $\begin{array}{l}\text { Case studies of } 2 \text { pts w/ unilat } \\
\text { coronal craniosynostosis \& Down } \\
\text { syndrome }\end{array}$ \\
\hline Tan et al., 2013 & Yes & $\begin{array}{l}\text { Pts w/ unilat coronal craniosynosto- } \\
\text { sis only }\end{array}$ \\
\hline $\begin{array}{l}\text { Thompson et al., } \\
2018\end{array}$ & No & NA \\
\hline Vogel et al., 2014 & No & $\begin{array}{l}\text { Overlapping pt population confirmed } \\
\text { w/ authors; included for unique } \\
\text { data }\end{array}$ \\
\hline $\begin{array}{l}\text { Yarbrough et al., } \\
2014\end{array}$ & Yes & $\begin{array}{l}\text { Case series of } 5 \mathrm{pts} \mathrm{w} / \text { mixed suture } \\
\text { types }\end{array}$ \\
\hline $\begin{array}{l}\text { Zubovic et al., } \\
2015\end{array}$ & Yes & $\begin{array}{l}\text { Pts w/ unilat lambdoid craniosynos- } \\
\text { tosis only }\end{array}$ \\
\hline
\end{tabular}

$\mathrm{NA}=$ not applicable; $p t s=$ patients. 
TABLE 2. Results of quality assessment of methodology

\begin{tabular}{|c|c|c|c|c|c|c|c|}
\hline Authors \& Year & Selection Bias & Study Design & Confounders & Blinding & Data Collection Methods & Analyses & Global Rating \\
\hline Abbott et al., 2012 & Moderate & Moderate & Weak & Moderate & Moderate & Weak & Weak \\
\hline Arts et al., 2018 & Strong & Moderate & Moderate & Moderate & Moderate & Moderate & Strong \\
\hline Bonfield et al., 2016 & Strong & Moderate & Weak & Moderate & Moderate & Weak & Weak \\
\hline Esparza \& Hinojosa, 2008 & Strong & Weak & Weak & Moderate & Moderate & Weak & Weak \\
\hline Garber et al., 2017 & Strong & Moderate & Moderate & Moderate & Moderate & Strong & Strong \\
\hline Ghenbot et al., 2015 & Moderate & Moderate & Weak & Moderate & Moderate & Weak & Weak \\
\hline Han et al., 2016 & Strong & Moderate & Weak & Moderate & Moderate & Moderate & Moderate \\
\hline Shah et al., 2011 & Strong & Moderate & Weak & Moderate & Moderate & Moderate & Moderate \\
\hline Thompson et al., 2018 & Strong & Moderate & Strong & Moderate & Moderate & Strong & Strong \\
\hline Vogel et al., 2014 & Strong & Moderate & Weak & Moderate & Moderate & Moderate & Moderate \\
\hline
\end{tabular}

ing 316 articles. This yielded 28 studies that underwent full-text analysis, of which 15 did not meet the inclusion criteria of 1) having more than $50 \%$ of patients present with sagittal synostosis; and 2) reporting on quantitative results. Three of the studies had overlapping cohorts for which unique outcomes were not reported (Table 1). Of the 10 studies included in the qualitative analysis, only 3 reported appropriate data from nonoverlapping cohorts that could be used for meta-analysis.

Seven of the 28 full-text analysis studies originated from Washington University School of Medicine, with confirmed or potential overlapping cohorts. Therefore, for each key question only the study with the largest cohort was included in the literature review. This process resulted in 10 studies with unique cohorts for specific outcomes. There were 4 weak, 3 moderate, and 3 strong papers (Table 2).

\section{Cohort Description}

Patient demographic characteristics are outlined in Table 3. The cohort size of the meta-analysis was 688 patients, with 303 (44\%) children undergoing endoscopeassisted craniosynostosis surgery and 385 (56\%) children undergoing open repair for craniosynostosis. The age of the endoscopic cohort was younger than that of the open cohort (median 2.9, mean 3.4 months, and median 5.6, mean 15.5 months, respectively).

In the literature review, the reported age of the patients in the endoscopic and open cohorts ranged from $2.9^{11}$ to $4.1^{8}$ months and $4.8^{4}$ to $15.5^{16}$ months, respectively. The proportion of male patients in the studies treated by endoscopic and open procedures ranged from $68 \%$ to $75 \%$ and $42 \%$ to $76 \%$, respectively. The follow-up ranged from 4.2 months to 95.4 months.

\section{Perioperative Outcomes}

\section{Estimated Blood Loss}

Endoscope-assisted craniosynostosis surgery has a significantly lower estimated blood loss compared to open craniotomies, based on 3 studies (SMD $-1.57 \mathrm{ml} / \mathrm{kg}$, 95\% CI -1.75 to $-1.39 ; \mathrm{p}<0.001$ ) (Fig. 2A). From the literature review, Abbott et al. ${ }^{1}$ similarly reported medians of $4.1 \mathrm{ml} /$ $\mathrm{kg}$ and $59.4 \mathrm{ml} / \mathrm{kg}$ when comparing endoscopic to open procedures.

\section{Length of Stay}

Endoscope-assisted craniosynostosis surgery has a significantly shorter LOS compared to open craniotomies, based on 2 studies (SMD -1.66 days, 95\% CI -1.86 to -1.46; p < 0.001) (Fig. 2B). Thompson et al. ${ }^{44}$ conducted a multicenter retrospective study analyzing 933 propensity score-matched children and reported a median LOS of 2 and 4 days for endoscopic and open surgery, respectively. Abbott et al. ${ }^{1}$ also described a shorter LOS for endoscopic surgery compared to open surgery, with medians of 1 day and 3 days, respectively. A Spanish study ${ }^{8}$ measured mean time of hospitalization as a consequence of postoperative complications and found that endoscopic osteotomies (11.2 days) resulted in shorter stays compared to open sagittal suturectomy, open sagittal suturectomy with frontal dismantling, and total cranial vault remodeling $(12.4,11.5$, and 16.2 days, respectively).

\section{Operating Times}

Endoscope-assisted craniosynostosis surgery had a significantly lower operating time compared to open craniotomies, based on 2 studies (SMD -1.68 days, 95\% CI -1.87 to $-1.48 ; \mathrm{p}<0.001$ ) (Fig. $2 \mathrm{C}$ ). Likewise, Thompson et al. ${ }^{44}$ and Abbott et al. ${ }^{1}$ reported medians of 1.16 and 2 hours for endoscopic procedures and 2.16 and 6 hours for open procedures.

\section{Transfusions}

Six studies ${ }^{1,2,4,11,16,44}$ reported a lower need for intraoperative and postoperative transfusions for patients undergoing endoscopic procedures compared to open cranial surgery. Endoscopic procedures showed a transfusion rate ranging from $0 \% \%^{1}$ to $26 \%^{2,44}$ of patients and open procedures ranged from $16 \%{ }^{44}$ to $100 \%{ }^{1}$ (Table 4).

\section{Complications}

Eight studies $1,2,4,8,11,16,39,44$ reported on complications of open and endoscopic treatment of sagittal synostosis (Table 5). These studies all used different metrics to analyze rates of complications at various time points, including during the operation, during the hospital stay, and at various lengths of follow-up. Although statistical analysis was not reported, 6 studies reported equal or lower rates of 
complications for endoscopically treated patients. Han et al. observed complication rates at 4 time points and found no statistical difference between endoscopic and open surgery (range, $p=0.140$ to $p=0.921$ ). Most notably, 3 studies $^{2,8,11}$ reported a lower reoperation rate for endoscopic techniques compared to open surgery.

\section{Cosmetic Outcomes}

Two studies from different patient populations compared postoperative cranial index, both of which showed no statistical difference. Abbott et al. ${ }^{1}$ reported a postoperative cranial index of 0.77 and 0.75 for endoscopic and open procedures, respectively, with no significant difference. Likewise, Shah et al..$^{39}$ also demonstrated a cranial index of 0.76 and $0.77(p=0.346)$ for endoscopic and open procedures. Finally, Ghenbot et al. ${ }^{12}$ looked at cranial vault volume, showing no significant difference for the endoscopic and open cohorts $(\mathrm{p}=0.31)$, although the patients in this cohort were probably also all analyzed by Shah et al. ${ }^{39}$

\section{Cost of Treatment}

Three studies looked at the cost of craniosynostosis treatment. Abbott et al. ${ }^{1}$ and Vogel et al. ${ }^{45}$ analyzed the total cost of treating craniosynostosis, including the medical cost of hospital and physician fees, orthotic cost of helmet fittings, and indirect patient costs of travel and lost work days. The median (range) of the endoscopic and open surgery cost was $\$ 23,377(\$ 20,987-\$ 24,977)$ and $\$ 55,121$ $(\$ 44,690-\$ 86,313)$, respectively, ${ }^{1}$ and the reported mean cost of endoscopic and open surgery was $\$ 37,356$ and $\$ 56,990$, respectively. ${ }^{45}$ Looking solely at medical costs, ${ }^{11}$ endoscopic procedures again were found to be cheaper $(\$ 21,203)$ than open procedures $(\$ 32,806)$.

\section{Discussion}

In this meta-analysis and literature review, we found that surgical treatment of sagittal synostosis by endoscope-assisted surgery was associated with shorter operating room times, shorter LOS, reduced rates of transfusion, and similar cosmetic results at last follow-up (as measured by cranial index), compared with open surgery. Important differences highlighted include the age at time of surgery, which was consistently younger for children undergoing endoscopic repair. The study by Esparza and Hinojosa ${ }^{8}$ shows the differences between North American and European treatment; despite the difficulty in performing a direct comparison, the inclusion of this study highlights how different healthcare systems will have an impact on treatment options. Although a myriad of techniques for both open and endoscopic repair have been reported, rendering comparisons difficult, our meta-analysis provides the most comprehensive synthesis of the available literature pertaining to the surgical treatment of sagittal synostosis with open and endoscopic methods.

\section{Perioperative Outcomes}

Endoscopic treatment of craniosynostosis has significantly less estimated blood loss than open surgery., 1,2,11,16 Consequently, the rate of transfusion has been found to be

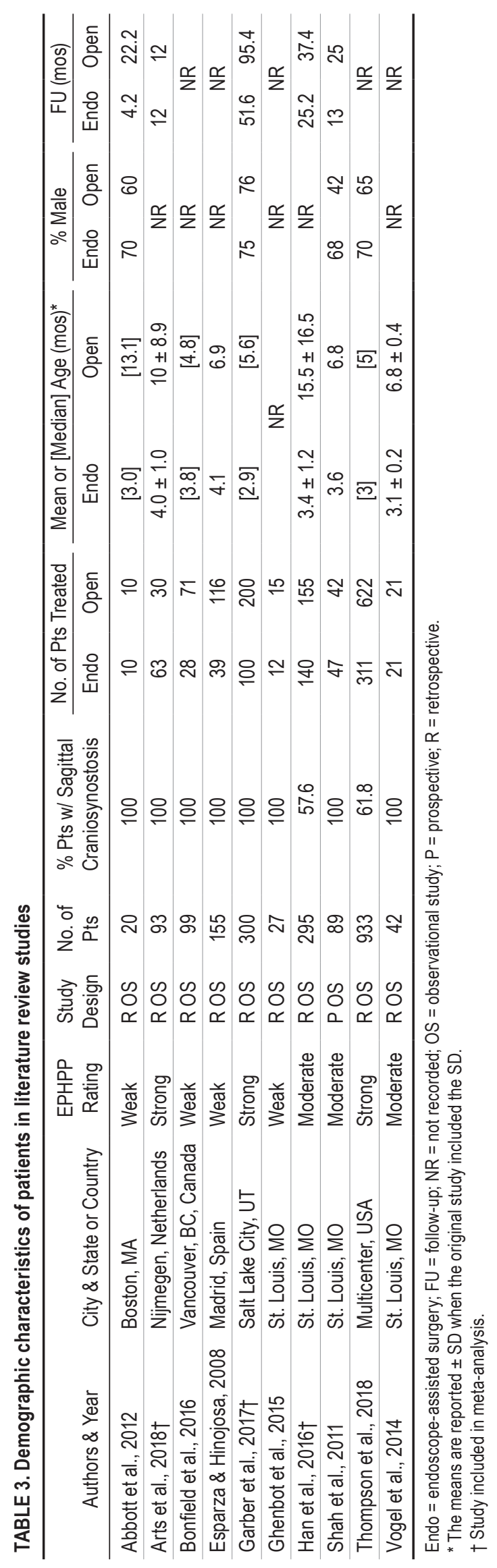


A. Estimated Blood Loss $(\mathrm{mL} / \mathrm{kg})$

Std diff Standard Lower Upper

in means error Variance limit limit Z-Value p-Value

$\begin{array}{cccccccc}\text { Garber, 2017 } & -1.162 & 0.131 & 0.017 & -1.420 & -0.905 & -8.848 & 0.000 \\ \text { Arts, 2018 } & -1.896 & 0.262 & 0.069 & -2.409 & -1.383 & -7.243 & 0.000 \\ \text { Han, 2016 } & -1.948 & 0.142 & 0.020 & -2.226 & -1.671 & -13.768 & 0.000 \\ \text { Fixed } & -1.570 & 0.090 & 0.008 & -1.747 & -1.393 & -17.377 & 0.000 \\ \text { Random } & -1.654 & 0.293 & 0.086 & -2.228 & -1.080 & -5.647 & 0.000\end{array}$

B. Length of Stay (days)

$\begin{array}{cccccccc}\text { Garber, 2017 } & -0.956 & 0.129 & 0.017 & -1.208 & -0.704 & -7.435 & 0.000 \\ \text { Han, 2016 } & -2.798 & 0.164 & 0.027 & -3.120 & -2.477 & -17.072 & 0.000 \\ \text { Fixed } & -1.657 & 0.101 & 0.010 & -1.856 & -1.459 & -16.385 & 0.000 \\ \text { Random } & -1.874 & 0.921 & 0.849 & -3.680 & -0.068 & -2.034 & 0.042\end{array}$

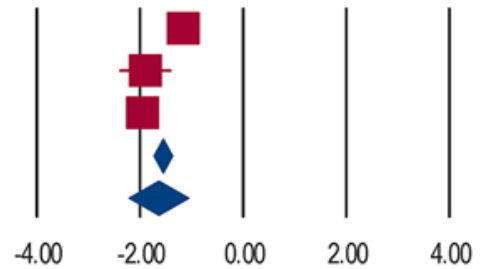

C. Length of Operative Time (hours)

$\begin{array}{crrrrrrr}\text { Garber, 2017 } & -2.849 & 0.169 & 0.029 & -3.180 & -2.518 & -16.868 & 0.000 \\ \text { Hen, 2016 } & -1.041 & 0.124 & 0.015 & -1.285 & -0.798 & -8.383 & 0.000 \\ \text { Fixed } & -1.676 & 0.100 & 0.010 & -1.872 & -1.480 & -16.747 & 0.000 \\ \text { Random } & -1.942 & 0.904 & 0.817 & -3.713 & -0.170 & -2.148 & 0.032\end{array}$

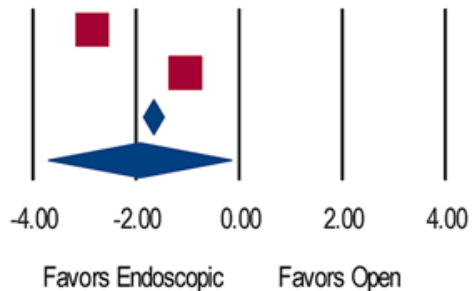

FIG. 2. Meta-analysis of perioperative measures. Std diff in means = SMDs. Figure is available in color online only.

TABLE 4. Transfusion rates between endoscopic and open treatments of sagittal craniosynostosis

\begin{tabular}{llcc}
\hline \multirow{2}{*}{ Authors \& Year } & \multicolumn{1}{c}{ Treatment } & \multicolumn{2}{c}{ Transfusion (\%) } \\
\cline { 2 - 4 } Abbott et al., 2012 & Endo & Open \\
\cline { 2 - 4 } & Platelets & 0 & $100^{*}$ \\
\cline { 2 - 4 } & FFP & 0 & 20 \\
\cline { 2 - 4 } & Cryoprecipitate & 0 & 10 \\
\cline { 2 - 4 } & Albumin & $30^{*}$ & $90^{*}$ \\
\hline Arts et al., 2018 & pRBC & 26 & 81 \\
\hline Bonfield et al., 2016 & & 7.1 & 17.0 \\
\hline Garber et al., 2017 & Endo vs CVR & $13^{*}$ & $83^{*}$ \\
\cline { 2 - 4 } & Endo vs SSC & 13 & 23 \\
\hline Han et al., 2016 & Intraop pRBC & $5.0^{*}$ & $96.1^{*}$ \\
\cline { 2 - 4 } & Postop pRBC & $5.0^{*}$ & $39.4^{*}$ \\
\hline Thompson et al., 2018 & RBC blood products & $26^{*}$ & $81^{*}$ \\
\cline { 2 - 4 } & Coagulation products & $3^{*}$ & $16^{*}$ \\
\hline
\end{tabular}

$\mathrm{CVR}=$ total cranial vault reconstruction; FFP = fresh frozen plasma; $\mathrm{pRBC}=$ packed red blood cells; SSC = open sagittal strip craniectomy.

${ }^{*} p<0.05$

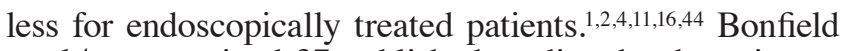
et al. ${ }^{4}$ summarized 37 published studies that have investigated blood transfusion rates in craniofacial procedures, although they did not report any studies that directly compared endoscopic to open procedures. Although blood transfusion safety has improved over time, infants have a greater incidence of adverse outcomes than adults ( 37 vs 13 cases per 100,000 red blood cells transfused, respectively). ${ }^{15,27}$ This is most often due to complications such as transfusion-related acute lung injury (TRALI) and transfusion-related circulatory overload (TACO). Therefore, it is important to minimize the need for transfusion when performing surgery on infants. In their multicenter study of 31 institutions, Thompson et al. ${ }^{44}$ regretted the documented inaccuracies of blood loss estimates and sought alternatives to study this important metric.

The length of operating time and LOS for endoscopically treated patients was significantly shorter with endoscope-assisted correction of sagittal synostosis, as seen in 5 studies. ${ }^{1,8,11,16,44}$ Although the American studies show LOS means ranging from 1 to 4 days, Esparza and Hinojosa $^{8}$ admit that their mean time of 11.9 days is unacceptable; their longer hospital stays seen in sagittal expansive osteotomies (12.4 days) and sagittal holocranial dismantling (16.2 days) are related to postoperative complications. This further suggests that the less invasive endoscopic techniques may reduce operating time and hospital stay. 
TABLE 5. Complications in patients with sagittal craniosynostosis undergoing endoscopic and open surgery

\begin{tabular}{|c|c|c|c|c|c|c|c|}
\hline \multirow[b]{2}{*}{ Authors \& Year } & \multicolumn{2}{|c|}{ No. of Pts } & \multirow[b]{2}{*}{ Complication } & \multicolumn{2}{|c|}{ Endoscopic } & \multicolumn{2}{|c|}{ Open } \\
\hline & Endo & Open & & $\%$ & No. of Pts & $\%$ & No. of Pts \\
\hline Abbott et al., 2012 & 10 & 10 & Postop emergency visits & 0.0 & 0 & 30.0 & 3 \\
\hline \multirow[t]{3}{*}{ Arts et al., 2018} & \multirow[t]{3}{*}{63} & \multirow[t]{3}{*}{30} & Intraop complications & 1.6 & 1 & 3.3 & 1 \\
\hline & & & Postop complications & 4.7 & 3 & 3.3 & 1 \\
\hline & & & Reoperation & 1.6 & 1 & 3.3 & 1 \\
\hline Bonfield et al., 2016 & 28 & 71 & Cardiovascular or wound healing & 0.0 & 0 & 0.0 & 0 \\
\hline \multirow[t]{9}{*}{ Esparza \& Hinojosa, 2008} & \multirow[t]{9}{*}{39} & \multirow[t]{9}{*}{116} & Reoperation & 2.6 & 1 & 9.5 & 11 \\
\hline & & & Wound infection & 2.6 & 1 & 0.0 & 0 \\
\hline & & & Subgaleal hematoma & 0.0 & 0 & 5.2 & 6 \\
\hline & & & Infected hematoma & 0.0 & 0 & 3.4 & 4 \\
\hline & & & Dural tear & 0.0 & 0 & 0.8 & 1 \\
\hline & & & Craniolacunae & 0.0 & 0 & 2.6 & 3 \\
\hline & & & Plate scarring & 0.0 & 0 & 1.7 & 2 \\
\hline & & & Postop hyperthermia & 10.3 & 4 & 15.5 & 18 \\
\hline & & & Infection* & 1.7 & 4 & 2.3 & 16 \\
\hline Garber et al., 2017 & 100 & 200 & Revision surgery & 1.0 & 1 & 7.0 & 14 \\
\hline \multirow[t]{4}{*}{ Han et al., 2016† } & \multirow[t]{4}{*}{140} & \multirow[t]{4}{*}{155} & Surgical complications & 2.1 & 3 & 1.3 & 2 \\
\hline & & & Intraop durotomies & 3.6 & 5 & 7.8 & 12 \\
\hline & & & Postop complications & 3.6 & 5 & 4.5 & 7 \\
\hline & & & Readmit $<30$ days & 1.4 & 2 & 1.3 & 2 \\
\hline Shah et al., 2011† & 47 & 42 & Wound revision & 2.1 & 1 & 2.4 & 1 \\
\hline \multirow[t]{5}{*}{ Thompson et al., 2018} & \multirow[t]{5}{*}{311} & \multirow[t]{5}{*}{622} & Hypotension requiring pressors & 3 & 8 & 4 & 23 \\
\hline & & & Venous air embolism & 1 & 4 & 1 & 5 \\
\hline & & & Hypothermia, temp $<35^{\circ} \mathrm{C}$ & 22 & 70 & 26 & 160 \\
\hline & & & Postop intubation & 2 & 6 & 10 & 60 \\
\hline & & & Cardiac arrest & 0 & 0 & 0.2 & 1 \\
\hline
\end{tabular}

\section{Complications}

Eight studies s, $2,4,8,11,16,39,44$ seem to support an equivalent or decreased complication rate for endoscopically assisted surgeries compared to open surgery. Future research should document the most common or most severe complications at each stage of treatment to provide the opportunity for analysis across studies. None of the included studies reported a higher incidence of injury to the sagittal sinus due to endoscopic surgery compared to open surgery. Because it is a novel technique, endoscopic surgery encompasses a large variability in outcomes and complications between different surgeons and procedures.

\section{Cosmetic Outcomes}

It has not yet been clearly defined how to best measure the postoperative aesthetic improvements after craniosynstosis surgery. The average cranial index (i.e., maximal cranial width/length) of children younger than 3 years of age was measured at $0.815 .{ }^{31}$ In children with sagittal synostosis, the cranial index is as low as $0.65 . .^{14,35}$ Our study shows that both endoscopic and open corrections, with cranial index ranging from 0.75 to 0.77 , are able to achieve comparable postoperative results. ${ }^{1,39}$ Ghenbot et al. ${ }^{12}$ analyzed cranial vault volume in addition to cranial index and found no difference in cranial vault volume, assuaging the concern that molding helmet therapy would lead to volume restriction. Future studies evaluating these techniques must take into account variability in outcomes among children as well as other measures of cosmesis, including parent or patient impression and satisfaction.

\section{Cost of Treatment}

In 3 different populations, ${ }^{1,11,45}$ the cost of endoscopic treatment with helmet therapy follow-up was found to be lower than the cost of open surgery, with differences ranging from $\$ 11,603$ to $\$ 31,744$. The difference is mostly attributable to the more invasive and extensive nature of open cranial surgery, often requiring ICU observation, transfusions, or a higher rate of revision. The costs of helmets were reported in all included studies; however, there are several indirect costs and also additional time needed for postoperative helmet servicing that have not been measured in the published literature. Furthermore, there may be unaccounted obstacles and unknown patient or parent impressions of helmet usage that have not been studied. The long-term efficacy and costs require ongoing research. 


\section{Strengths and Limitations}

Strengths of this study include an extensive search of the current literature, strict adherence to PRISMA guidelines, and quality of evidence analysis by EPHPP protocol. Currently, there exists no randomized controlled trial comparing the surgical approaches of endoscopic and open sagittal suture repair. Given the data suggesting absence of equipoise between the two techniques, it is unlikely that such a trial would be conducted. Ultimately, the findings of this meta-analysis require confirmation by larger, multicenter studies with extended follow-up.

Only 3 studies met PRISMA criteria for full meta-analysis; this low number indicates the need for future studies. The studies included in this review consisted mostly of moderate and weak observational studies. One must also consider the selection bias due to preference of surgeons or institutions and shifts of practice over time. There have yet to be any studies that examine patient or parent satisfaction, or the required duration and comfort of helmet usage. It is also evident that there is a tradeoff between the potential benefits of endoscopic repair and the disadvantage of the length of time spent in a helmet. These compromises are mediated by parental preferences, which are difficult to capture in current literature. Future studies aimed at assessing "value-based medicine" by using methodologies such as decision-tree analyses may elucidate the benefit of endoscopic repair.

Furthermore, there is still a lack of understanding regarding the variability of endoscopic outcomes and, therefore, longer follow-up and further analyses are indicated. The current meta-analysis was additionally limited by the heterogeneity of suture types in some studies. ${ }^{16}$ Given the clinical and surgical heterogeneity that we have identified, it is of value to conduct future observational studies that separate different entities and account for patient and surgical variability. Given the dearth of data available for metaanalysis, interstudy heterogeneity could not be calculated.

\section{Conclusions}

Endoscope-assisted correction of sagittal synostosis has some benefits over open surgical repair. Endoscopic procedures are associated with lower estimated blood loss, operating time, days in hospital, and transfusion rates. Current evidence in the literature comparing endoscopic and open sagittal craniosynostosis repair is mostly of weak to moderate quality-only 3 papers were found to be strong. Although these early studies suggest several benefits of endoscopic procedures, consideration is needed for each individual family to understand the usage of helmets and unknown long-term outcomes. Future large prospective registries or randomized controlled trials are required to validate the findings of this study.

\section{References}

1. Abbott MM, Rogers GF, Proctor MR, Busa K, Meara JG: Cost of treating sagittal synostosis in the first year of life. $\mathbf{J}$ Craniofac Surg 23:88-93, 2012

2. Arts S, Delye H, van Lindert EJ: Intraoperative and postoperative complications in the surgical treatment of craniosynostosis: minimally invasive versus open surgical procedures. J Neurosurg Pediatr 21:112-118, 2018
3. Bir SC, Ambekar S, Notarianni C, Nanda A: Odilon Marc Lannelongue (1840-1911) and strip craniectomy for craniosynostosis. Neurosurg Focus 36(4):E16, 2014

4. Bonfield CM, Sharma J, Cochrane DD, Singhal A, Steinbok P: Minimizing blood transfusions in the surgical correction of craniosynostosis: a 10-year single-center experience. Childs Nerv Syst 32:143-151, 2016

5. Chan JW, Stewart CL, Stalder MW, St Hilaire H, McBride L, Moses MH: Endoscope-assisted versus open repair of craniosynostosis: a comparison of perioperative cost and risk. J Craniofac Surg 24:170-174, 2013

6. Di Rocco F, Arnaud E, Renier D: Evolution in the frequency of nonsyndromic craniosynostosis. J Neurosurg Pediatr 4:21-25, 2009

7. Dvoracek LA, Skolnick GB, Nguyen DC, Naidoo SD, Smyth MD, Woo AS, et al: Comparison of traditional versus normative cephalic index in patients with sagittal synostosis: measure of scaphocephaly and postoperative outcome. Plast Reconstr Surg 136:541-548, 2015

8. Esparza J, Hinojosa J: Complications in the surgical treatment of craniosynostosis and craniofacial syndromes: apropos of 306 transcranial procedures. Childs Nerv Syst 24:1421-1430, 2008

9. Farber SJ, Nguyen DC, Skolnick GB, Naidoo SD, Smyth MD, Patel KB: Anthropometric outcome measures in patients with metopic craniosynostosis. J Craniofac Surg 28:713-716, 2017

10. Fearon JA, McLaughlin EB, Kolar JC: Sagittal craniosynostosis: surgical outcomes and long-term growth. Plast Reconstr Surg 117:532-541, 2006

11. Garber ST, Karsy M, Kestle JRW, Siddiqi F, Spanos SP, RivaCambrin J: comparing outcomes and cost of 3 surgical treatments for sagittal synostosis: a retrospective study including procedure-related cost analysis. Neurosurgery 81:680-687, 2017

12. Ghenbot RG, Patel KB, Skolnick GB, Naidoo SD, Smyth MD, Woo AS: Effects of open and endoscopic surgery on skull growth and calvarial vault volumes in sagittal synostosis. J Craniofac Surg 26:161-164, 2015

13. Ghosh TD, Skolnick G, Nguyen DC, Sun H, Patel K, Smyth $\mathrm{MD}$, et al: Calvarial thickness and diploic space development in children with sagittal synostosis as assessed by computed tomography. J Craniofac Surg 25:1050-1055, 2014

14. Gociman B, Marengo J, Ying J, Kestle JR, Siddiqi F: Minimally invasive strip craniectomy for sagittal synostosis. J Craniofac Surg 23:825-828, 2012

15. Goodnough LT: Risks of blood transfusion. Anesthesiol Clin North America 23:241-252, v, 2005

16. Han RH, Nguyen DC, Bruck BS, Skolnick GB, Yarbrough CK, Naidoo SD, et al: Characterization of complications associated with open and endoscopic craniosynostosis surgery at a single institution. J Neurosurg Pediatr 17:361-370, 2016

17. Hashim PW, Patel A, Yang JF, Travieso R, Terner J, Losee JE, et al: The effects of whole-vault cranioplasty versus strip craniectomy on long-term neuropsychological outcomes in sagittal craniosynostosis. Plast Reconstr Surg 134:491-501, 2014

18. Jimenez DF, Barone CM: Endoscopic craniectomy for early surgical correction of sagittal craniosynostosis. J Neurosurg 88:77-81, 1998

19. Jimenez DF, Barone CM, McGee ME, Cartwright CC, Baker CL: Endoscopy-assisted wide-vertex craniectomy, barrel stave osteotomies, and postoperative helmet molding therapy in the management of sagittal suture craniosynostosis. J Neurosurg 100 (5 Suppl Pediatrics):407-417, 2004

20. Kapp-Simon KA, Speltz ML, Cunningham ML, Patel PK, Tomita T: Neurodevelopment of children with single suture craniosynostosis: a review. Childs Nerv Syst 23:269-281, 2007 
21. Keshavarzi S, Hayden MG, Ben-Haim S, Meltzer HS, Cohen SR, Levy ML: Variations of endoscopic and open repair of metopic craniosynostosis. J Craniofac Surg 20:1439-1444, 2009

22. Keshavarzi S, Meltzer H, Cohen SR, Breithaupt A, Ben-Haim $\mathrm{S}$, Newman CB, et al: The risk of growing skull fractures in craniofacial patients. Pediatr Neurosurg 46:193-198, 2010

23. Kohan E, Wexler A, Cahan L, Kawamoto HK, Katchikian H, Bradley JP: Sagittal synostotic twins: reverse pi procedure for scaphocephaly correction gives superior result compared to endoscopic repair followed by helmet therapy. J Craniofac Surg 19:1453-1458, 2008

24. Kolar JC: An epidemiological study of nonsyndromal craniosynostoses. J Craniofac Surg 22:47-49, 2011

25. Lane LC: Pioneer craniectomy for relief of mental imbecility due to premature sutural closure and microcephalus. JAMA 267:230, 1992

26. Lannelongue OM: De la craniectomie chez les microcéphales, chez les enfants arriérés et chez les jeunes sujets présentants, avec ou sans crises épileptiformes, de troubles moteurs ou psychiques. Congr Franc de Chir Paris 5:73-81, 1891

27. Lavoie J: Blood transfusion risks and alternative strategies in pediatric patients. Paediatr Anaesth 21:14-24, 2011

28. Le MB, Patel K, Skolnick G, Naidoo S, Smyth M, Kane A, et al: Assessing long-term outcomes of open and endoscopic sagittal synostosis reconstruction using three-dimensional photography. J Craniofac Surg 25:573-576, 2014

29. Lee HQ, Hutson JM, Wray AC, Lo PA, Chong DK, Holmes $\mathrm{AD}$, et al: Changing epidemiology of nonsyndromic craniosynostosis and revisiting the risk factors. J Craniofac Surg 23:1245-1251, 2012

30. Liberati A, Altman DG, Tetzlaff J, Mulrow C, Gøtzsche PC, Ioannidis JP, et al: The PRISMA statement for reporting systematic reviews and meta-analyses of studies that evaluate health care interventions: explanation and elaboration. PLoS Med 6:e1000100, 2009

31. Likus W, Bajor G, Gruszczyńska K, Baron J, Markowski J, Machnikowska-Sokołowska M, et al: Cephalic index in the first three years of life: study of children with normal brain development based on computed tomography. Sci World J 2014:502836, 2014

32. MacKinnon S, Proctor MR, Rogers GF, Meara JG, Whitecross S, Dagi LR: Improving ophthalmic outcomes in children with unilateral coronal synostosis by treatment with endoscopic strip craniectomy and helmet therapy rather than fronto-orbital advancement. J AAPOS 17:259-265, 2013

33. MacKinnon S, Rogers GF, Gregas M, Proctor MR, Mulliken JB, Dagi LR: Treatment of unilateral coronal synostosis by endoscopic strip craniectomy or fronto-orbital advancement: ophthalmologic findings. J AAPOS 13:155-160, 2009

34. Mehta VA, Bettegowda C, Jallo GI, Ahn ES: The evolution of surgical management for craniosynostosis. Neurosurg Focus 29(6):E5, 2010

35. Murray DJ, Kelleher MO, McGillivary A, Allcutt D, Earley MJ: Sagittal synostosis: a review of 53 cases of sagittal suturectomy in one unit. J Plast Reconstr Aesthet Surg 60:991-997, 2007

36. Nguyen DC, Patel KB, Skolnick GB, Naidoo SD, Huang AH, Smyth MD, et al: Are endoscopic and open treatments of metopic synostosis equivalent in treating trigonocephaly and hypotelorism? J Craniofac Surg 26:129-134, 2015

37. Nowaková M, Kordoš P, Hladík M, Medřická H, Rosický J, Kaleta E, et al: Endoskopické operační řešení kraniosynostóz z pohledu dětského intenzivisty. Přehledové články 16:308311,2015

38. Rogers GF, Wood BC, Amdur RL, Jeelani Y, Reddy S, Proctor MR, et al: Treatment type is associated with population hand preferences in patients with unilateral coronal synostosis: implications for functional cerebral lateralization. Plast Reconstr Surg 136:782e-788e, 2015
39. Shah MN, Kane AA, Petersen JD, Woo AS, Naidoo SD, Smyth MD: Endoscopically assisted versus open repair of sagittal craniosynostosis: the St. Louis Children's Hospital experience. J Neurosurg Pediatr 8:165-170, 2011

40. Shamseer L, Moher D, Clarke M, Ghersi D, Liberati A, Petticrew M, et al: Preferred reporting items for systematic review and meta-analysis protocols (PRISMA-P) 2015: elaboration and explanation. BMJ 350:g7647, 2015

41. Siu A, Rogers GF, Myseros JS, Khalsa SS, Keating RF, Magge SN: Unilateral coronal craniosynostosis and Down syndrome. J Neurosurg Pediatr 13:568-571, 2014

42. Tan SP, Proctor MR, Mulliken JB, Rogers GF: Early frontofacial symmetry after correction of unilateral coronal synostosis: frontoorbital advancement vs endoscopic strip craniectomy and helmet therapy. J Craniofac Surg 24:1190-1194, 2013

43. Thomas BH, Ciliska D, Dobbins M, Micucci S: A process for systematically reviewing the literature: providing the research evidence for public health nursing interventions. Worldviews Evid Based Nurs 1:176-184, 2004

44. Thompson DR, Zurakowski D, Haberkern CM, Stricker PA, Meier PM, Bannister C, et al: Endoscopic versus open repair for craniosynostosis in infants using propensity score matching to compare outcomes: a multicenter study from the Pediatric Craniofacial Collaborative Group. Anesth Analg 126:968-975, 2018

45. Vogel TW, Woo AS, Kane AA, Patel KB, Naidoo SD, Smyth MD: A comparison of costs associated with endoscope-assisted craniectomy versus open cranial vault repair for infants with sagittal synostosis. J Neurosurg Pediatr 13:324-331, 2014

46. Yarbrough CK, Smyth MD, Holekamp TF, Ranalli NJ, Huang $\mathrm{AH}$, Patel KB, et al: Delayed synostoses of uninvolved sutures after surgical treatment of nonsyndromic craniosynostosis. J Craniofac Surg 25:119-123, 2014

47. Zubovic E, Woo AS, Skolnick GB, Naidoo SD, Smyth MD, Patel KB: Cranial base and posterior cranial vault asymmetry after open and endoscopic repair of isolated lambdoid craniosynostosis. J Craniofac Surg 26:1568-1573, 2015

\section{Disclosures}

The authors report no conflict of interest concerning the materials or methods used in this study or the findings specified in this paper.

\section{Author Contributions}

Conception and design: Yan, Ibrahim. Acquisition of data: Yan, Abel, Anderson. Analysis and interpretation of data: Yan, Abel. Drafting the article: Yan, Abel, Ibrahim. Critically revising the article: all authors. Reviewed submitted version of manuscript: all authors. Approved the final version of the manuscript on behalf of all authors: Yan. Statistical analysis: Alotaibi. Administrative/ technical/material support: Ibrahim. Study supervision: Yan, Ibrahim.

\section{Supplemental Information Companion Papers}

Yan H, Abel TJ, Alotaibi NM, Anderson M, Niazi TN, Weil AG, et al: A systematic review of endoscopic versus open treatment of craniosynostosis. Part 2: the nonsagittal single sutures. DOI: 10.3171/2018.4.PEDS17730.

\section{Correspondence}

Han Yan: The Hospital for Sick Children, Toronto, ON, Canada. hhan.yan@mail.utoronto.ca. 